\title{
Oxygen exchange flux between sediment and water in an intertidal sandflat, measured in situ by the eddy-correlation method
}

\author{
Tomohiro Kuwae ${ }^{1, *}$, Koichiro Kamio ${ }^{2}$, Tetsunori Inoue ${ }^{1}$, Eiichi Miyoshi ${ }^{1}$, \\ Yusuke Uchiyama ${ }^{3}$ \\ ${ }^{1}$ Coastal and Estuarine Environment Research Group, Port and Airport Research Institute, 3-1-1, Nagase, \\ Yokosuka 239-0826, Japan \\ ${ }^{2}$ Tokyo-Kyuei Co., 6906-10, Shiba-tsurugamaru, Kawaguchi 333-0866, Japan \\ ${ }^{3}$ Institute of Geophysics and Planetary Physics, University of California at Los Angeles, 3637 Geology, Los Angeles, \\ California 90095-1567, USA
}

\begin{abstract}
High temporal-resolution fluctuations in oxygen concentration and vertical velocity were measured over an intertidal sandflat (water depth $<69 \mathrm{~cm}$ ) using an oxygen microelectrode and an acoustic Doppler velocimeter, in order to estimate oxygen flux across the sediment-water interface using the eddy-correlation method. The effect of flux estimate procedures, including noise removal and extraction of fluctuating components, was investigated. The estimated oxygen effluxes from the sediment ranged from -3.2 to $6.6 \mathrm{mmol} \mathrm{O}_{2} \mathrm{~m}^{-2} \mathrm{~h}^{-1}$ in the light and from -14.5 to $-6.6 \mathrm{mmol}$ $\mathrm{O}_{2} \mathrm{~m}^{-2} \mathrm{~h}^{-1}$ in the dark. The oxygen-uptake fluxes in the dark were markedly higher than those measured by a conventional enclosure technique. High-frequency turbulence and/or noise $(>5 \mathrm{~Hz})$ observed in the vertical velocity and oxygen concentration data made little contribution to the total oxygen flux (0 to $7 \%$ ). However, trends (steady change over a longer time scale) caused significant artifacts in the estimated fluxes for several cases. Thus, removal of trends from raw time-series data is recommended. The co-spectrum of the fluctuating components of vertical velocity and oxygen concentration revealed that the oxygen flux at a frequency band between 0.3 and $1.4 \mathrm{~Hz}$ (at a period from 0.7 to $3.3 \mathrm{~s}$ ) was a major contributor to the total oxygen flux. This frequency was consistent with the dominant frequency of vertical velocity, indicating that transport and exchange of porewater and overlying water by wind-induced waves may be crucial processes to dissolved oxygen flux between permeable sandy sediments and shallow waters.
\end{abstract}

KEY WORDS: Sedimentary oxygen flux $\cdot$ Microelectrode $\cdot$ Acoustic Doppler velocimeter $\cdot$ ADV · Permeable sediment · Banzu tidal flat

Resale or republication not permitted without written consent of the publisher

\section{INTRODUCTION}

Conventionally, oxygen-exchange fluxes across the sediment-water interface are measured by 2 approaches: (1) tracking changes in oxygen concentration in the overlying water of enclosed benthic systems, including intact sediment core incubation in the laboratory and in situ benthic chamber deployment; and (2) determining oxygen concentration profiles in the benthic boundary layer by microsensors (e.g. Jørgensen \& Boudreau 2001, Reimers et al. 2001, Wenzhöfer \& Glud 2004, de Beer et al. 2005, and references therein). However, both approaches have been reported to have limitations. Hydrodynamic forcing, such as waves and currents, is almost never represented in enclosed benthic systems, even though it is known to have a significant effect on solute fluxes between sediment and water (e.g. Jørgensen \& Des 
Marais 1990, Huettel \& Webster 2001). Moreover, complete enclosing of benthic systems may enhance artifacts for permeable sandy sediments, because the water exchange generated by horizontal pressure gradients and/or turbulence is blocked (e.g. Huettel \& Gust 1992). The oxygen concentration profiling method, in turn, measures a local point flux using a 1-dimensional concentration gradient; hence, the effects of bioturbation and bioirrigation occurring away from the oxygen microsensor cannot be determined.

A newly developed technique to measure exchange fluxes is the eddy-correlation method. This method has been used to measure such energy and material fluxes in coastal marine environments as heat under sea ice (Shirasawa et al. 1997) and suspended sediment in an estuary (Dyer et al. 2004). Berg et al. (2003) first applied the eddy-correlation method to measure oxygen-uptake fluxes by aquatic sediments. The eddycorrelation method can overcome the disadvantages of the 2 conventional methods because of its (1) applicability for in situ measurements without creating artifacts (no alterations of in situ environment) and (2) lack of limitations regarding seabed characteristics such as sediment permeability, topography, and vegetation. The eddy-correlation method is based on the principle that vertical flux is expressed by an average of the product of fluctuating vertical velocity and passive scalar, such as dissolved oxygen. However, a practical protocol and quality controls have not yet been investigated thoroughly for the eddy-correlation method applied to oxygen flux, particularly to extracting fluctuating components from the raw time series of vertical velocity and oxygen concentration and to determining sufficient sampling time.

Here, we report on high time-resolution fluctuations of oxygen concentration and vertical current velocity in the overlying water during both daytime and nighttime in an intertidal sandflat, and the oxygen flux across the sediment-water interface estimated by the eddy-correlation method. The calculation methodology, including fluctuating component extraction and the length of sampling time required, is discussed in order to estimate the oxygen flux accurately. We also describe the importance of wind-induced waves as a driving force of oxygen transport and flux in the permeable sandy sediment ecosystem, by comparing the spectral peak frequencies.

\section{MATERIALS AND METHODS}

Study site. The study site, Banzu intertidal sandflat, is located on the east coast of Tokyo Bay (Japan) and covers an area of $7.6 \mathrm{~km}^{2}$. Tokyo Bay receives nutrient loading from a human population of ca. 26 million and is subjected to heavy eutrophication and anoxia in bottom waters over a wide area in summer. Tides are semi-diurnal, with amplitudes from 0.5 to $1.6 \mathrm{~m}$ (Guo \& Yanagi 1994). The site (35²4.2' N, $\left.139^{\circ} 53.4^{\prime} \mathrm{E}\right)$ experiences emersion and immersion during each tide.

We conducted 6 series of in situ measurements from daytime (Cases 1 to 4 ) to nighttime (Cases 5 and 6) on February 25, 2004 (Table 1). The slope of the seabed at the site is gentle $\left(0.07 \mathrm{~cm} \mathrm{~m}^{-1}\right)$. Sediments are characterized by well-sorted fine sand (>99.5\%), with a median grain size of 188 to $217 \mu \mathrm{m}$ and an intrinsic permeability $(k)$ of ca. $7 \times 10^{-12} \mathrm{~m}^{2}$. Total organic carbon and total nitrogen contents in the top $3 \mathrm{~cm}$ of sediment on the measurement day were $0.630 \pm 0.022 \mathrm{mg} \mathrm{C} \mathrm{g}^{-1}$ dry wt (mean $\pm \mathrm{SE}, \mathrm{n}=$ 12) and $0.110 \pm 0.004 \mathrm{mg} \mathrm{N} \mathrm{g}^{-1}$ dry wt (mean $\pm \mathrm{SE}$, $\mathrm{n}=12$ ), respectively.

There is no macro-vegetation, and pennate diatoms dominate the epibenthic microalgal flora. Chlorophyll a content in the top $1 \mathrm{~cm}$ of sediment was $5.7 \pm$ $0.7 \mu \mathrm{g} \mathrm{cm}^{-3}$ bulk sed. (mean $\pm \mathrm{SE}, \mathrm{n}=12$ ) on the measurement day. Bubble formation on the sediment surface by microalgal photosynthesis, which can affect oxygen-flux estimation, was not observed at the site. The ghost shrimp Callianassa japonica (Decapoda: Thalassinidea) dominated $28 \%$ of the macrofauna on a density basis $\left(41 \pm 24\right.$ ind. $\left.\mathrm{m}^{-2}\right)($ mean $\pm \mathrm{SE}, \mathrm{n}=8)$ and $91 \%$ of the macrofauna on a soft body dry weight basis $\left(0.7 \pm 0.7\right.$ g dry $\left.w t \mathrm{~m}^{-2}\right)($ mean $\pm \mathrm{SE}, \mathrm{n}=8)$.

Table 1. Ranges of overlying water parameters during each time series. Mean values are indicated in parentheses

\begin{tabular}{|cccccc|}
\hline & $\begin{array}{c}\text { Measurement } \\
\text { period (min) }\end{array}$ & $\begin{array}{c}\text { Depth } \\
(\mathrm{cm})\end{array}$ & $\begin{array}{c}\text { Temperature } \\
\left({ }^{\circ} \mathrm{C}\right)\end{array}$ & \multicolumn{2}{c|}{$\begin{array}{c}\text { Dissolved oxygen } \\
(\% \text { air saturation) }\end{array}$} \\
\hline Case 1 & 18 & $38-46(42)$ & $10.7-10.9(10.8)$ & $288.6-298.6(293.5)$ & $95-98(97)$ \\
Case 2 & 12 & $63-69(65)$ & $11.0-11.8(11.4)$ & $297.2-311.0(304.0)$ & $102-103(102)$ \\
Case 3 & 13 & $53-60(56)$ & $11.3-11.6(11.4)$ & $301.3-305.8(303.6)$ & $97-97(97)$ \\
Case 4 & 40 & $39-57(49)$ & $11.6-12.5(11.8)$ & $282.5-289.9(286.0)$ & $100-103(101)$ \\
Case 5 & 16 & $36-42(39)$ & $13.3-14.0(13.7)$ & $264.0-266.6(267.0)$ & $98-99(98)$ \\
Case 6 & 35 & $36-38(37)$ & $11.8-12.0(11.8)$ & $271.3-275.5(273.5)$ & $97-98(98)$ \\
\hline
\end{tabular}


Measurements. Current velocity was measured using an acoustic Doppler velocimeter (ADV) (Vector, Nortek). The ADV measures 3-dimensional velocity in a cylindrical measurement volume (14 mm height, $14 \mathrm{~mm}$ in diameter) located on the centerline, $157 \mathrm{~mm}$ from the base of 3 acoustic transducers (Fig. 1). The velocity was corrected against the speed of sound varying with temperature and salinity of the ambient seawater. The accuracy documented by the manufacturer is $\pm 0.5 \%$ of the measured value $\pm 0.1 \mathrm{~cm} \mathrm{~s}^{-1}$.

Oxygen concentration was measured using a Clark-type oxygen microelectrode (OX-10, Unisense). The sensor has a $4 \mu \mathrm{m}$ diameter tip and a $<0.3 \mathrm{~s}$ response time for a $90 \%$ response to concentration changes (documented by the manufacturer). The sensor was connected to a pico-ampere meter (PA-2000, Unisense). The pico-ampere meter has a response time of $<0.05 \mathrm{~s}$ (documented by the manufacturer). Preliminary laboratory experiments confirmed that a combination of the pico-ampere meter and the oxygen microelectrode was capable of detecting small concentration changes stably with a $<0.3$ s response time.

The ADV and the oxygen microelectrode were mounted on a rigid stepladder (Fig. 1). The stepladder was installed at a different location for each case. In addition, the stepladder was placed in a direction perpendicular to the dominant direction of tidal currents for each case, in order to avoid artifacts in flux estimates due to disturbance of current fields by the stepladder pods. The position of the measurement volume was adjusted 7 to $17 \mathrm{~cm}$ above the sediment sur-

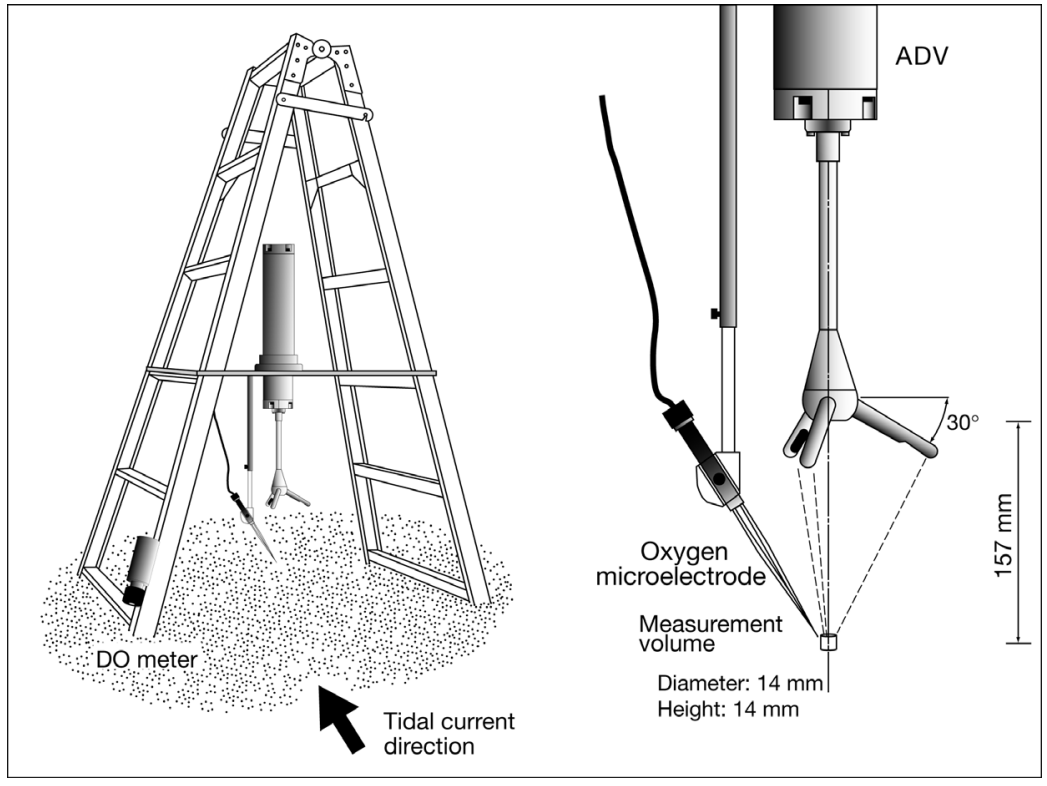

Fig. 1. Schematic diagram of sensor installation (ADV: acoustic Doppler velocimeter; DO: dissolved oxygen) face. The tip of the microelectrode was positioned immediately adjacent $(<5 \mathrm{~mm})$ to the measurement volume of the ADV. Current velocity and oxygen concentration were simultaneously measured at a frequency of $20 \mathrm{~Hz}$ and recorded on a data logger (NR2000, Keyence). The ADV, the pico-ampere meter, and the data logger were powered individually by internal batteries to minimize synchronized noise.

To exclude errors in oxygen concentration data due to possible drift or sensitivity variation in the oxygen microelectrode during measurement periods, the oxygen data were crosschecked with the alternative oxygen data simultaneously obtained using a galvanic cell-type sensor (DO meter) (MDO-I, Sanyo-Sokki) mounted on the stepladder (Fig. 1). Only the timeseries data that were consistent with the DO meter data were used for oxygen-flux calculation (Fig. 2).

Flux calculation. Procedure for flux calculation is summarized in Fig. 2. In addition, details and the principle of the eddy-correlation method are described by Berg et al. (2003). Briefly, advection is supposed to be the dominant solute transport in the water column above the diffusive boundary layer. Under such a condition, the vertical solute flux is:

$$
J=W C
$$

where $J$ is the instantaneous flux, $w$ is the vertical current velocity, and $C$ is the solute concentration. Both $W$ and $C$ are also decomposed into 2 components: $W=\bar{W}+$ $W^{\prime}$ and $C=\bar{C}+C^{\prime}$, where $\bar{W}$ is the mean vertical velocity, $W^{\prime}$ is the vertical fluctuating velocity, $\bar{C}$ is the mean solute concentration, and $C^{\prime}$ is the fluctuating solute concentration. The separations are substituted into Eq. (1), and then averaged over a period of time significantly longer than turbulent fluctuations; averages of both $w^{\prime}$ and $C^{\prime}$ become equal to zero by this operation. The mean vertical velocity $(\bar{W})$ is assumed to vanish, then Eq. (1) can be expressed as:

$$
\bar{J}=\overline{w^{\prime} C^{\prime}}
$$

where $\bar{J}$ is the mean flux over time. Therefore, the extraction methodology of these 2 fluctuating components, $W^{\prime}$ and $C^{\prime}$, from measured time-series data is critical for accurate quantification of oxygen flux, which is discussed in detail below. Since $\bar{J}$ is calculated as the time-averaged flux, changes in the instantaneous flux, varying with environmental conditions such as light and temperature, are averaged over the duration of the time series used for calculation. 


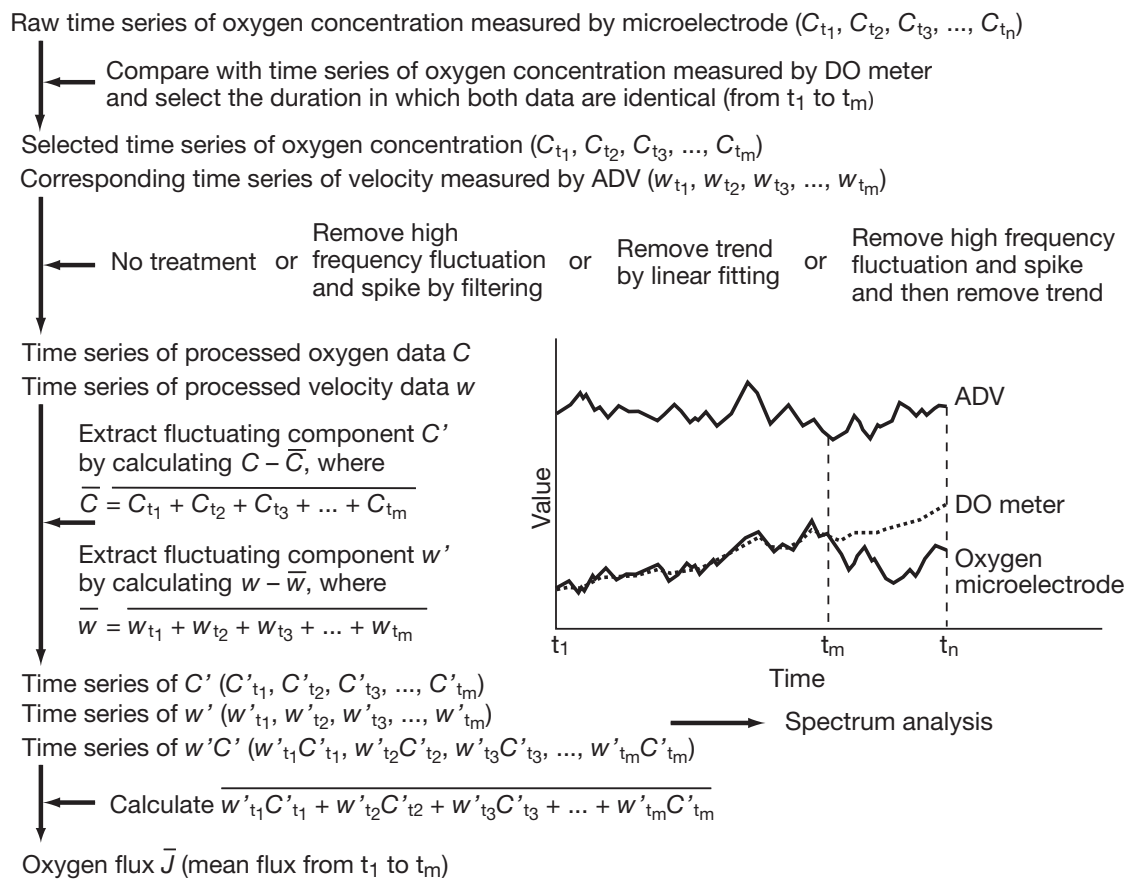

Fig. 2. Procedure for flux calculation

period because of inevitable inhomogeneities and 'folding' errors in the lowfrequency spectrum when using a fastFourier transformation (Frieche et al. 1991, von Storch \& Zwiers 1999).

\section{RESULTS AND DISCUSSION}

\section{Environmental conditions}

The duration of the time series used for flux calculations ranged from 12 to 40 min (Table 1). Changes in water depth during each measurement were 2 to $18 \mathrm{~cm}$. Changes in temperature and oxygen concentration in the overlying water during each measurement were 0.2 to $0.9^{\circ} \mathrm{C}$ and 2.6 to $13.8 \mu \mathrm{M} \mathrm{O}_{2}$, respectively. Percent air saturation of oxygen exhibited almost saturated values for all cases.

Maximum wave height ranged from 3 to $9 \mathrm{~cm}$ (Table 2). Directional changes against major current direction (perpen-

To investigate the effects of turbulence and noise in high-frequency components, $w^{\prime}$ and $C^{\prime}$ were low pass filtered to $5 \mathrm{~Hz}$ (Dyer et al. 2004), and spikes were removed from filtered data by replacing variations $>3 \mathrm{SD}$ with an interpolated value (cf. French \& Clifford 1992). Few data were removed as spikes. The calculated fluxes using the filtered data were compared with those using the unfiltered data. To examine the fluctuation characteristics of vertical velocity, oxygen concentration, and oxygen flux, the spectra of $W^{\prime}$ and $C^{\prime}$ and the 1-sided cospectrum of $W^{\prime} C^{\prime}$ were analyzed using a fast-Fourier transformation of the time series of $W^{\prime}$ and $C^{\prime}$. The relative contribution of different frequencies of oxygen flux to the total oxygen flux can be evaluated by the co-spectrum analysis of $W^{\prime} C^{\prime}$ (Frieche et al. 1991, Berg et al. 2003). We described only the spectra and co-spectra with frequencies $>1 / 30$ of the length of each measurement dicular to the stepladder) during each measurement ranged from \pm 4 to $\pm 10^{\circ}$. The mean velocities of horizontal and upward vertical currents ranged from 13.8 to $24.1 \mathrm{~cm} \mathrm{~s}^{-1}$ and from -1.2 to $1.0 \mathrm{~cm} \mathrm{~s}^{-1}$, respectively.

\section{Time series of vertical velocity and oxygen concentration}

Temporal variation in oxygen concentration throughout the measurement period showed a significant linear change over time (trend) for all cases ( $\mathrm{n}=$ 14000 to 47400 , p < 0.0001) (Fig. 3), although the coefficient of determination in linear fitting was variable $\left(r^{2}=0.02\right.$ to 0.97$)$. Since the microelectrode data were consistent with the DO meter data, errors due to drift or sensitivity variation did not account for the trend.

Table 2. Maximum wave height and ranges of current direction and velocity during each time series. Sensor position indicates distance from the sediment surface. Angles against the major current direction (perpendicular to the stepladder) are given as current direction. Velocity values are averages for $1 \mathrm{~min}$; the data are filtered but not detrended. Mean values are indicated in parentheses

\begin{tabular}{|cccccc|}
\hline & $\begin{array}{c}\text { Maximum } \\
\text { wave height }(\mathrm{cm})\end{array}$ & $\begin{array}{c}\text { Sensor } \\
\text { position }(\mathrm{cm})\end{array}$ & $\begin{array}{c}\text { Current } \\
\left.\text { direction }{ }^{\circ}\right)\end{array}$ & $\begin{array}{c}\text { Horizontal } \\
\text { velocity }\left(\mathrm{cm} \mathrm{s}^{-1}\right)\end{array}$ & $\begin{array}{c}\text { Upward vertical } \\
\text { velocity }\left(\mathrm{cm} \mathrm{s}^{-1}\right)\end{array}$ \\
\hline Case 1 & 5 & 17 & \pm 7 & $9.8-19.4(16.9)$ & -0.7 to $-0.1(-0.4)$ \\
Case 2 & 3 & 17 & \pm 8 & $11.8-18.1(13.8)$ & 0.0 to $1.4(1.0)$ \\
Case 3 & 4 & 17 & \pm 4 & $20.4-26.3(24.1)$ & -1.4 to $-0.7(-1.2)$ \\
Case 4 & 5 & 17 & \pm 9 & $11.8-17.0(13.9)$ & -0.6 to $0.3(-0.2)$ \\
Case 5 & 9 & 14 & \pm 6 & $14.9-16.8(15.5)$ & -1.2 to $-0.5(-0.9)$ \\
Case 6 & 9 & 7 & \pm 10 & $14.3-18.9(16.1)$ & -1.4 to $-0.7(-1.0)$ \\
\hline
\end{tabular}




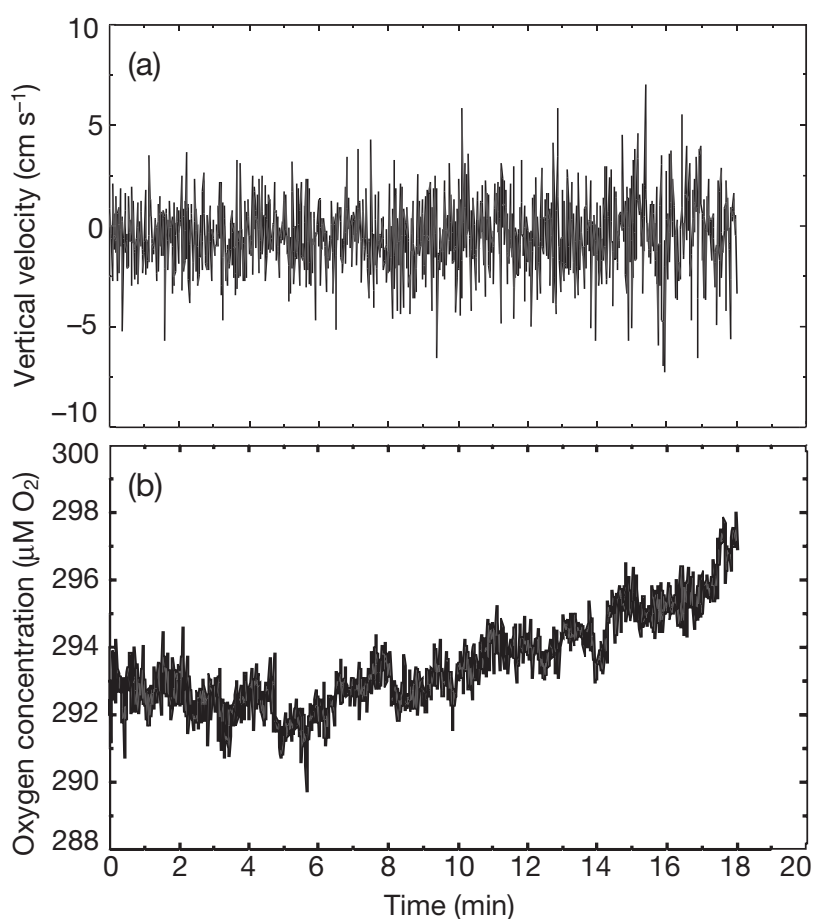

Fig. 3. Raw time series of (a) vertical velocity and (b) oxygen concentration throughout the measurement period (Case 1). Data were re-sampled with frequencies $<1 \mathrm{~Hz}$ to improve clarity. Positive velocity values indicate upward direction. A non-smooth inflection point is seen in the time series of oxygen concentration (5 to 6 min)

Hence, the trend presumably reflected a long-term net change in oxygen concentration in the water column. Vertical velocity did not show a steady change throughout the measurement period $\left(r^{2}<0.02\right)$ (Fig. 3), yet linear fitting was significant for all cases $(\mathrm{n}=14000$ to $47400, \mathrm{p}<0.0001)$.

The vertical velocity and the oxygen concentration exhibited a synchronized rhythmic fluctuation, with a period of 1 to $3 \mathrm{~s}$ on a short time scale for all cases (Fig. 4). For example, in Case 1, the oxygen concentration was high when the direction of the vertical velocity was upward, indicating that oxygenrich water was rhythmically advected upward from the benthic boundary layer. This correlation resulted in a net oxygen transport from the sediment. Obviously, oxygen was supplied through active photosynthesis by microphytobenthos on the sediment surface under a sufficient amount of irradiance for Case 1. Conversely, there was an inverse correlation in the fluctuation patterns between the oxygen concentration and the vertical velocity in the dark (Cases $5 \& 6)$, i.e. the oxygen concentration was low when the direction of the vertical velocity was upward, due to oxygen consumption by the sediment (data not shown).

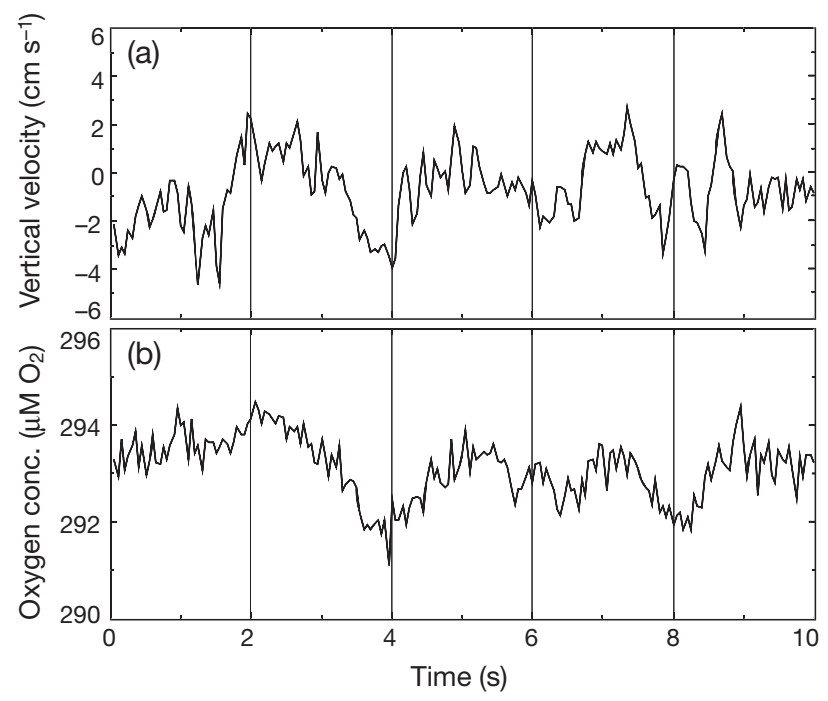

Fig. 4. Raw time series of (a) vertical velocity and (b) oxygen concentration measured $17 \mathrm{~cm}$ above the sediment at a frequency of $20 \mathrm{~Hz}$ (Case 1). Positive velocity values indicate upward direction. Irradiance in air was 650 to $970 \mu \mathrm{mol}$ photons $\mathrm{m}^{-2} \mathrm{~s}^{-1}$

\section{Effects of high- and low-frequency fluctuations and trends}

High-frequency components $(>5 \mathrm{~Hz}$ ) were detected in the vertical velocity and oxygen concentration fluctuating at a period of 1 to $3 \mathrm{~s}$ (Fig. 4). Possibly both real turbulence and noise were included in the highfrequency components for the vertical velocity. However, most of the high-frequency components in the oxygen concentration were caused by noise, because the oxygen microelectrode used here had a $<0.3 \mathrm{~s}$ response time. Spectrum analysis revealed that the contribution of high-frequency components to the total power spectral density of $w^{\prime}$ was low $(6.8 \pm 3.0 \%)$ (mean $\pm \mathrm{SE}, \mathrm{n}=6$ ) and that of high-frequency components of $C^{\prime}$ to their total spectral density was moderate $(13.7 \pm 2.2 \%)($ mean $\pm S E, n=6)$ for all cases (Fig. 5). To investigate the relative contribution of high-frequency components to the total flux, oxygen fluxes were calculated for both the raw data and the filtered data (Table 3). Extraction of $W^{\prime}$ and $C^{\prime}$ was performed by subtracting $\bar{W}$ and $\bar{C}$ for the raw data or filtered data from the corresponding $w$ and $C$ (see Fig. 2). Results showed that high-frequency components (>5 Hz) in $w^{\prime}$ and $C^{\prime}$ had little effect on the total oxygen flux (0 to $7 \%$ ). Analysis of cumulative co-spectrum of $W^{\prime} C^{\prime}$ allows us to determine the relative contribution of different frequencies to the total flux (Frieche et al. 1991, Berg et al. 2003). The co-spectrum of $W^{\prime} C^{\prime}$ confirmed that the contribution of high frequencies to the total flux was negligible for all cases $(0.9 \pm 0.5 \%)($ mean $\pm \mathrm{SE}, \mathrm{n}=6)$ 


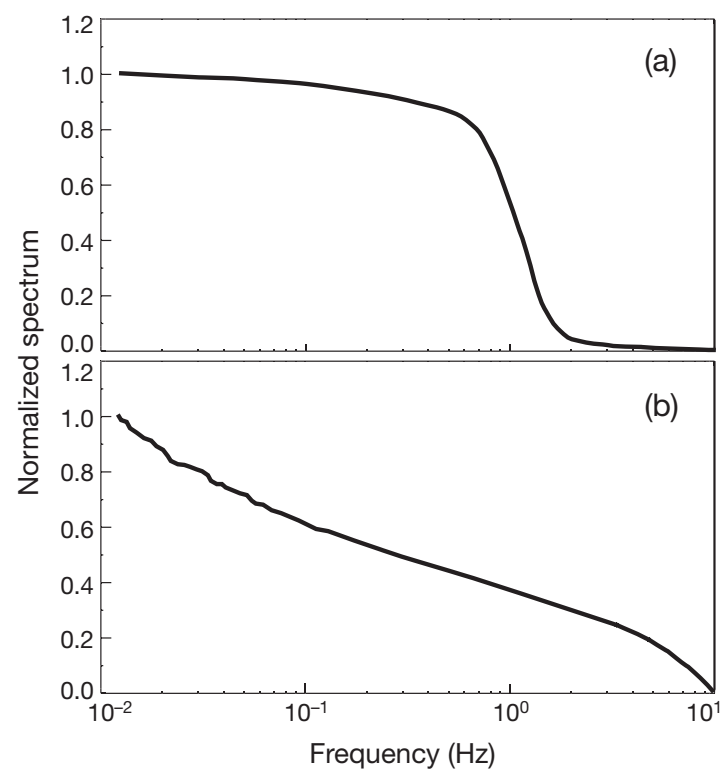

Fig. 5. Representative data for the cumulative spectra of (a) $w^{\prime}$ and (b) $C^{\prime}$ (Case 4). The spectra were cumulated from the high-frequency side. The frequency band with a steep gradient indicates a major contributor to the total spectrum. Detrended but unfiltered data were used for spectrum calculation

(Fig. 6). Noise contained in the high-frequency band of the velocity and oxygen concentration was presumably random and non-correlated (white noise), resulting in the negligible contribution to the total flux. In addition, little contribution of high-frequency components suggested that the oxygen microelectrode used here, with a $<0.3 \mathrm{~s}$ response time, would capture important fluctuations (Berg et al. 2003).

Steady changes in velocity and concentration over longer time scales (trends) have been reported to cause errors in extraction of fluctuating components from time-series data, because of overestimation of turbulent fluctuations (Panofsky \& Dutton 1984). Since time-variant fluctuations in velocity and concentration seem to be often observed in in situ environments, detrending may be a prerequisite to calculate fluxes.

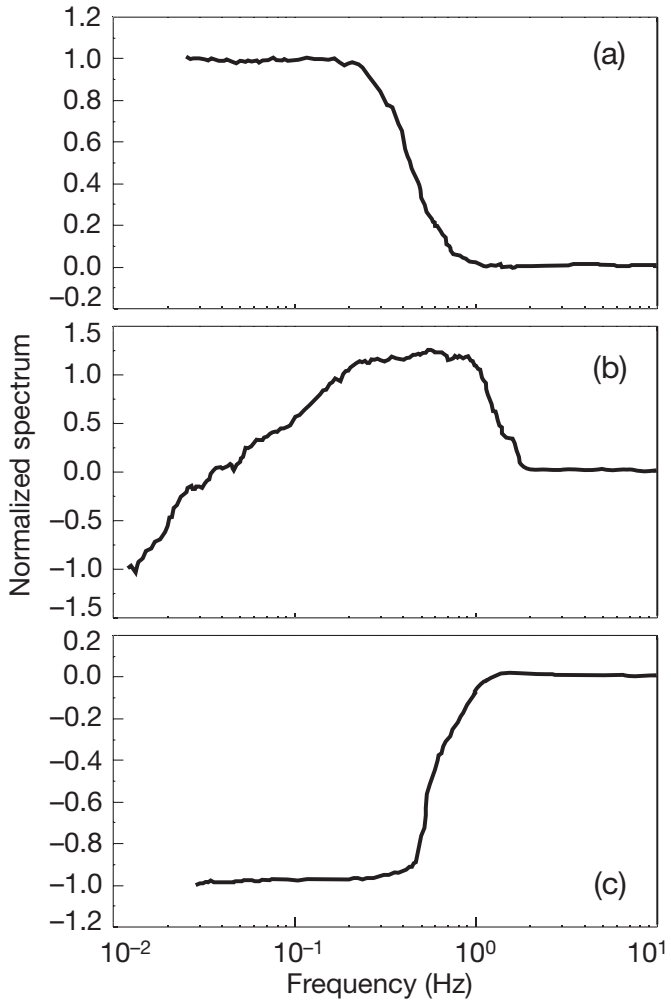

Fig. 6. Cumulative co-spectrum of $w^{\prime} C^{\prime}$ in (a) the dominant period of oxygen production (Case 1), (b) the intermediate period (Case 4), (c) and the dominant period of oxygen consumption (Case 5). The spectrum was cumulated from the high-frequency side. The frequency band with a steep gradient indicates a major contributor to the total co-spectrum (total oxygen flux). Positive values indicate effluxes from the sediment. Detrended but unfiltered data were used for co-spectrum calculation for each case

For example, in our case, the trend observed in the oxygen concentration (Fig. 3) was probably caused by a long-term net change in the oxygen concentration in the overlying water, but was not the real turbulent fluctuation needed for eddy-correlation. Technically, trends have been removed by subtracting lowfrequency variations, evaluated by linear or curve fit-

Table 3. Oxygen fluxes $\left(\mathrm{mmol} \mathrm{O}_{2} \mathrm{~m}^{-2} \mathrm{~h}^{-1}\right)$ calculated after various data treatments. Positive values indicate effluxes from the sediment

\begin{tabular}{|c|c|c|c|c|c|c|}
\hline & \multirow{2}{*}{ Non-treatment } & \multirow{2}{*}{ Filtering } & \multirow[t]{2}{*}{ Detrending } & \multirow{2}{*}{$\begin{array}{c}\text { Filtering } \\
\& \text { detrending }\end{array}$} & \multicolumn{2}{|c|}{ Filtering \& block averaging ${ }^{a}$} \\
\hline & & & & & Mean \pm SE & $\mathrm{n}$ \\
\hline Case 1 & 11.0 & 10.3 & 7.0 & 6.6 & $5.1 \pm 0.8$ & 8 \\
\hline Case 2 & 46.5 & 46.0 & 2.9 & 2.6 & $0.1 \pm 1.7$ & 5 \\
\hline Case 3 & -3.9 & -3.9 & 0.5 & 0.5 & $0.4 \pm 0.9$ & 6 \\
\hline Case 4 & -3.3 & -3.3 & -3.2 & -3.2 & $-2.5 \pm 0.6$ & 19 \\
\hline Case 5 & -14.7 & -14.7 & -14.5 & -14.5 & $-13.8 \pm 1.1$ & 8 \\
\hline Case 6 & -6.5 & -6.4 & -6.6 & -6.6 & $-6.5 \pm 0.4$ & 17 \\
\hline
\end{tabular}


ting or by moving averages, from the original data. In this study, detrending was performed using linear fitting, and the calculated fluxes using the detrended data were compared with those using the raw data. Calculation of $W^{\prime}$ and $C^{\prime}$ was performed by subtracting $\bar{W}$ and $\bar{C}$ for the raw data or detrended data from the corresponding $w$ and $C$ (see Fig. 2). A marked difference in the calculated fluxes was observed between detrending and non-treatment for several cases (0 to $94 \%$ ) (Table 3). In particular, for Case 2, the steep slope of linear fitting and high fitness $\left(r^{2}=0.97\right)$ in the oxygen concentration appeared to cause substantial differences in the estimated fluxes. In contrast, no marked difference was found for Case 6, in which the slope of linear fitting and fitness were low. Nevertheless, our results suggest that detrending is needed when the eddy-correlation method is applied for strong time-variant conditions (Berg et al. 2003), which frequently occur in intertidal flat systems.

Detrending with linear or curve fitting, as well as with a moving average, has a limitation for the timeseries data that includes non-smooth inflection points, as seen in Fig. 3. Short-term flux measurements or averaging procedures would be an alternative strategy to minimize the effect of trends without using the fittings or moving averages, because the temporal variances of velocity and solute concentration may be smaller for shorter times. Therefore, we calculated oxygen fluxes by 'block averaging' (Table 3). Time series of filtered data for each case were divided into 2 min segments, and the flux for each segment was calculated according to Fig. 2. For instance, in Case 1 (total length of time series: $11.8 \mathrm{~min}$ ), 5 fluxes were calculated from 5 segments of $2 \mathrm{~min}$, and the last segment (1.8 $\mathrm{min}$ ) was not used for the flux calculation. It should be noted that these flux calculation results never include the contribution of the $<0.008 \mathrm{~Hz}$ frequency (a period of $>2 \mathrm{~min}$ ) component, that is, block averaging can lead to an error in total flux estimates due to the neglect of low-frequency contributions. Thus, a difference in the estimated flux between the block-average method and the filtering and detrending method could suggest a contribution of the $<0.008 \mathrm{~Hz}$ frequency to the total flux. Nevertheless, it is impossible to accurately separate low-frequency components into the real turbulent fluctuations that reflect sediment-water flux and the apparent time-variant fluctuations that are independent from the flux (e.g. Frieche et al. 1991, Dyer et al. 2004). Therefore, we have to compromise between exclusion of low-frequency flux contributions and the increase of uncertainty in estimated fluxes due to inclusion of time-variant fluctuations.

We described only the co-spectra with frequencies $>1 / 30$ of the duration of the time series because of inevitable inhomogeneities and 'folding' errors in the low-frequency spectrum when using a fast-Fourier transformation (Frieche et al. 1991, von Storch \& Zwiers 1999). However, the possibility of a lowfrequency $(<1 / 30$ of the duration of the time series) contribution to the total oxygen flux was indicated by the difference in the estimated flux between the blockaverage method and the filtering and detrending method. One explanation for the processes responsible for the low-frequency fluxes can be bioirrigationinduced flux, including ventilation by bivalves, polychaetes, and borrow-building shrimps (e.g. Koike \& Mukai 1983, Mukai \& Koike 1984, Kinoshita et al. 2003). Intermittent and periodic burrow irrigation is often observed for deposit feeders (e.g. Kristensen 1988, Forster \& Graf 1995, Stanzel \& Finelli 2004). Thus, the thalassinidean shrimp Callianassa japonica, which dominated our site, is a candidate for explaining the low-frequency oxygen flux. However, if the entire population within a footprint (the location where contributions to the oxygen flux are detected by the eddycorrelation method) is considered, the irrigationinduced oxygen fluctuation caused by individual C. japonica should be overlapped and more frequent, unless the irrigation of all individuals are in phase. Therefore, we concluded that the low-frequency oxygen flux was not caused by irrigation of C. japonica, but by unknown mechanisms.

\section{Evaluation of estimated fluxes}

The oxygen exchange fluxes observed in this study were comparable to those observed in previous studies at the site using the core-incubation method, in the light (range: 1.9 to $19.3 \mathrm{mmol} \mathrm{O}_{2} \mathrm{~m}^{-2} \mathrm{~h}^{-1}$, mean $\pm \mathrm{SE}$ : $7.7 \pm 1.0 \mathrm{mmol} \mathrm{O} \mathrm{m}^{-2} \mathrm{~h}^{-1}, \mathrm{n}=32$ ) and in the dark (range: -14.5 to $-0.5 \mathrm{mmol} \mathrm{O}_{2} \mathrm{~m}^{-2} \mathrm{~h}^{-1}$, mean $\pm \mathrm{SE}$ : -3.2 $\pm 0.6 \mathrm{mmol} \mathrm{O}_{2} \mathrm{~m}^{-2} \mathrm{~h}^{-1}, \mathrm{n}=32$ ) (Kuwae et al. 1998, T. Kuwae et al. unpubl. data). The high oxygen-uptake rates observed in Cases 5 and 6 were also comparable to results from the permeable sandy sediments of the Wümme River using the eddy-correlation method $\left(\right.$ mean $\left.\pm \mathrm{SE}: 8.8 \pm 0.7 \mathrm{mmol} \mathrm{O}_{2} \mathrm{~m}^{-2} \mathrm{~h}^{-1}\right)$ (Berg et al. 2003). However, there was great variation between cases in our results. The variation is attributed to either (1) true variability or (2) artifacts caused by our measurement system. For the former, differences in the measurement conditions, including irradiation and temperature, would affect the fluxes and induce the variation between cases. Moreover, the position of footprints differed between cases, because of differences in the installed position and direction of the stepladder. Hence, the great variation between cases may account for the horizontal and temporal heterogeneity of the actual oxygen fluxes. 
The possibility of artifacts may arise from sensor capabilities and the effect of the stepladder on the flow field of footprints. As for the sensor capabilities, our results should not be affected by the sensor specification, because (1) the contribution of high-frequency components $(>5 \mathrm{~Hz}$ ) to the total flux was small, which has been discussed above, and (2) a capacity for detecting small concentration changes with a $<0.3 \mathrm{~s}$ response time was provided by our pico-ampere meter and oxygen microelectrode, as was confirmed by preliminary laboratory experiments.

A footprint has been reported to be located upstream from the sensor position and to be oval shaped, with the longer axis being parallel to major current direction; factors affecting the area of footprints include the vertical position of the sensor and bed roughness (e.g. Kljun et al. 2002). Adjustment of the direction of the stepladder perpendicular to the dominant direction of tidal currents for each case would have avoided creating artifacts in the flow field of the footprints. However, since we did not examine the accurate location and area of the footprint using numerical simulations, we are unable to absolutely demonstrate that the stepladder did not have an effect on the estimated fluxes.

The result of the block-average method does, however, suggest that the effect of the stepladder was negligible and that our system can be applied for sites influenced by waves. This is because, even though the environmental conditions during the measurement were not stationary for all cases, the standard error of the fluxes calculated by block averaging was relatively small and comparable to that in previous studies at the site.

Another potential source of error might be that the mean vertical velocity was slightly off zero (Table 2 ). This probably occurs because the sediment surface is not completely flat and horizontal in natural environments. In addition, (1) use of the burst average instead of the ensemble average for mean velocity calculations and (2) the accuracy of the ADV could also be sources of error. However, the problem of non-zero vertical velocity has been reported to be negligible when applied for scalar flux calculation (e.g. Anthoni et al. 2004, Dyer et al. 2004).

\section{Importance of waves}

The cumulative spectrum of $w^{\prime}$ showed that the frequency band of 0.3 to $1.4 \mathrm{~Hz}(0.7$ to $3.3 \mathrm{~s})$ had a steep gradient (Fig. 5) and was a major contributor to the total spectrum power. This pattern was also detected in the time-series data (Fig. 4) and spectra of $W^{\prime}$ for all cases; the fluctuations of $W^{\prime}$ in the frequency band of 0.3 to $1.4 \mathrm{~Hz}$ accounted for $60.8 \pm 5.1 \%$ (mean $\pm \mathrm{SE}, \mathrm{n}=$
6) of the total variances. These frequencies were consistent with those in the power spectra of wave height at the site (the peak periods increase up to $4 \mathrm{~s}$ ), indicating that the orbital velocity induced by wind-driven waves dominated the hydrodynamics at our site (Uchiyama 2006). Moreover, the cumulative co-spectra of $W^{\prime} C^{\prime}$ in both the dominant periods of oxygen production (Cases 1 and 2) and the dominant periods of oxygen consumption (Cases 5 and 6) also had peaks in almost the same band as $w^{\prime}$ (Fig. 6). The 0.3 to $1.4 \mathrm{~Hz}$ frequency flux (co-spectrum) accounted for $84.0 \pm$ $9.1 \%$ (mean $\pm \mathrm{SE}, \mathrm{n}=4$ ) of the total fluxes. Therefore, we conclude that wave-induced vertical velocity with a predominant frequency of 0.3 to $1.4 \mathrm{~Hz}$ seems to be the most important process to control the oxygen flux between the sediment and the overlying water. Waveinduced oscillating flow drives advective transport of porewater and exchange between porewater and overlying water (Webb \& Theodor 1968, Riedl et al. 1972). Shallow-water waves can increase exchange between porewater and overlying water up to 3 orders of magnitude more than the exchange by molecular diffusion (Precht \& Huettel 2003, 2004). As a result of wave action, porewater is released from ripple crests, and overlying water is inundated into ripple troughs (Shum 1992, 1993, Ziebis et al. 1996a, Precht \& Huettel 2003, Precht et al. 2004). Possibly, our results directly captured these processes using the ADV and the oxygen microelectrode. In the dominant period of oxygen production, the oxygen-rich porewater formed by photosynthesis in the surface sediment may be forced into the overlying water and then transported upward as a passive solute by the vertical flow created by windinduced waves, with the predominant frequencies observed here. In the same manner, in the dominant period of oxygen consumption, the oxygen-poor porewater formed by respiration and chemical oxidation in the surface sediment may be forced into the overlying water by wave-induced flow. Moreover, release of porewater would be enhanced when sediment resuspension occurs, which may affect the oxygen flux. The importance of wind-induced waves, with a peak frequency around 0.1 to $2 \mathrm{~Hz}$, as transporters is likely to depend on water depth, because orbital flow velocities vary with (1) water depth, according to the infinitesimal wave theory (Phillips 1977), and (2) wave height, which is also affected by water depth in shallow waters (e.g. Uchiyama 2006).

A characteristic pattern was observed when oxygen production and consumption were close to being balanced (Cases 3 and 4) (Table 3, Fig. 6b). The cumulative co-spectrum of $w^{\prime} C^{\prime}$ showed that the direction of flux inverted within the spectrum; the oxygen-release flux occurred in the 1 to $2 \mathrm{~Hz}$ frequency band, and the oxygen-uptake flux occurred in the 0.01 to $0.5 \mathrm{~Hz}$ fre- 
quency band. The observation that the oxygen-release flux peaked at a frequency of 1 to $2 \mathrm{~Hz}$ was consistent with the peak spectrum of $w^{\prime}$ (Fig. 5); thus, it may be attributed to the wave-induced vertical transport of oxygen formed by the microphytobenthos on the sediment surface, which is the same mechanism as described above. However, to understand more about the oxygen-uptake flux that peaked at a frequency of 0.01 to $0.5 \mathrm{~Hz}$ further investigation is needed. Webster (1992) showed that the presence of waves leads to oscillatory motion within macrofaunal burrows. The motion is driven by the different pressures at the openings of burrows. Since thalassinidean shrimps, which dominated our site, often form a complex burrow system with multi-chambers and multi-openings (e.g. Mukai \& Koike 1984, Ziebis et al. 1996b, Shimoda \& Tamaki 2004), flow through the burrows would be very complicated. The friction to flow in the complex burrow and the geometry of the burrow, such as opening diameter and passage length, may affect the oscillatory burrow flow and could lower the flow frequency. Moreover, burrow walls are characterized by both higher microbial abundance and higher oxygen uptake than non-burrow sediments (e.g. Aller 1988, 2001, Kinoshita et al. 2003, Wenzhöfer \& Glud 2004). Thus, oxygen-poor burrow water could be released to the overlying water. These processes may explain why the oxygen-uptake flux peaked at a frequency of 0.01 to $0.5 \mathrm{~Hz}$. However, this effect, if any, may be dependent on the locality characterized by burrow densities and burrow structures.

Comparison of the results from the eddy-correlation method with those from conventional methods can also reveal the importance of waves and advective porewater transport for oxygen flux between permeable sediments and overlying water. The oxygen-uptake flux in the dark, measured by the core-incubation method using intact sediment cores taken from the same site on the following day of this study, was 1.0 to $1.5 \mathrm{mmol}$ $\mathrm{O}_{2} \mathrm{~m}^{-2} \mathrm{~h}^{-1}$ (T. Inoue unpubl. data), indicating only $23 \%$ of the flux measured in the dark by the eddycorrelation method at its maximum (Case 6, Table 3). This underestimate could be due to the exclusion of porewater pressure fluctuations by waves and ripple topography in the enclosed system (Precht \& Huettel 2003), even though wave-induced advective porewater transport supports a high oxygen-uptake rate associated with mineralization of dissolved and particulate organic matter in sandy sediments (Malan \& McLachlan 1991, Huettel \& Rusch 2000, Rusch \& Huettel 2000, de Beer et al. 2005).

In summary, the eddy-correlation method has marked advantages over conventional enclosure methods or vertical concentration profiling methods for accurate measurement of solute fluxes across the sedi- ment-water interface, particularly in shallow water ecosystems and/or sandy sediment ecosystems. Rigorous pre-analyses and extraction of fluctuating components from the time series of vertical velocity and oxygen concentration, by noise- and trend-removal operations, are needed in the eddy-correlation method. Determination of the length of sampling time and the appropriate detrending operation require a compromise between exclusion of low-frequency flux contributions and inclusion of the apparent fluctuations that are independent of the flux. The oxygen flux at a frequency band between 0.3 and $1.4 \mathrm{~Hz}$ is a major contributor to the total oxygen flux, and this result is in good agreement with Berg et al. (2003), being <1 Hz. Oscillating vertical flows induced by wind-driven waves are of importance for transport and exchange between porewater and overlying water, which contribute greatly to total oxygen flux between permeable sandy sediment and overlying water.

Acknowledgements. We thank S. Konuma and S. Hosokawa for their kind help during fieldwork. We also thank R. W. Elner and R. C. Ydenberg for helpful comments. The manuscript was greatly improved by the valuable comments of 5 anonymous reviewers. This research was supported by grants to T.K. from the Japan Railway Construction, Transport and Technology Agency (JRTT) Program for Promoting Fundamental Transport Technology Research and the Japan Society for the Promotion of Science (JSPS) Postdoctoral Fellowships for Research Abroad (FY2004).

\section{LITERATURE CITED}

Aller RC (1988) Benthic fauna and biogeochemical processes in marine sediments: the role of burrow structures. In: Blackburn TH, Sørensen J (eds) Nitrogen cycling in coastal marine environments. John Wiley \& Sons, New York, p 301-338

Aller RC (2001) Transport and reactions in the bioirrigated zone. In: Boudreau BP, Jørgensen BB (eds) The benthic boundary layer. Oxford University Press, New York, p 269-301

Anthoni PM, Freibauer A, Kolle O, Schulze ED (2004) Winter wheat carbon exchange in Thuringia, Germany. Agric For Meteorol 121:55-67

Berg P, Røy H, Janssen F, Meyer V, Jørgensen BB, Huettel M, de Beer D (2003) Oxygen uptake by aquatic sediments measured with a novel non-invasive eddy-correlation technique. Mar Ecol Prog Ser 261:75-83

de Beer D, Wenzhöfer F, Ferdelman TG, Boehme SE and 5 others (2005) Transport and mineralization rates in North Sea sandy intertidal sediments, Sylt-Rømø Basin, Wadden Sea. Limnol Oceanogr 50:113-127

Dyer KR, Christie MC, Manning AJ (2004) The effects of suspended sediment on turbulence within an estuarine turbidity maximum. Estuar Coast Shelf Sci 59:237-248

Forster S, Graf G (1995) Impact of irrigation on oxygen flux into the sediment: intermittent pumping by Callianassa subterranea and 'piston-pumping' by Lanice conchilega. Mar Biol 123:335-346

French JR, Clifford NJ (1992) Characteristics and 'event 
structure' of near-bed turbulence in a macro-tidal saltmarsh channel. Estuar Coast Shelf Sci 34:49-69

Frieche CA, Shaw WJ, Roger DP, Davidson KL and 6 others (1991) Air-sea fluxes and surface layer turbulence around a sea surface temperature front. J Geophys Res 96: 8593-8609

Guo X, Yanagi T (1994) Three dimensional structure of tidal currents in Tokyo Bay, Japan. La Mer 32:173-185

Huettel M, Gust G (1992) Solute release mechanisms from confined sediment cores in stirred benthic chambers and flume flows. Mar Ecol Prog Ser 82:187-197

Huettel M, Rusch A (2000) Transport and degradation of phytoplankton in permeable sediment. Limnol Oceanogr 45:534-549

Huettel M, Webster IT (2001) Porewater flow in permeable sediments. In: Boudreau BP, Jørgensen BB (eds) The benthic boundary layer. Oxford University Press, New York, p 144-179

Jørgensen BB, Boudreau BP (2001) Diagenesis and sediment-water exchange. In: Boudreau BP, Jørgensen BB (eds) The benthic boundary layer. Oxford University Press, New York, p 211-244

Jørgensen BB, Des Marais DJ (1990) The diffusive boundary layer of sediments: oxygen microgradients over a microbial mat. Limnol Oceanogr 35:1343-1355

Kinoshita K, Wada M, Kogure K, Furota T (2003) Mud shrimp burrows as dynamic traps and processors of tidal-flat materials. Mar Ecol Prog Ser 247:159-164

Kljun N, Rotach MW, Schmid HP (2002) A three-dimensional backward Lagrangian footprint model for a wide range of boundary-layer stratifications. Boundary-Layer Meteorol 103:205-226

Koike I, Mukai H (1983) Oxygen and inorganic nitrogen contents and fluxes in burrows of the shrimps Callianassa japonica and Upogebia major. Mar Ecol Prog Ser 12: 185-190

Kristensen E (1988) Benthic fauna and biogeochemical processes in marine sediments: microbial activities and fluxes. In: Blackburn TH, Sørensen J (eds) Nitrogen cycling in coastal marine environments. John Wiley \& Sons, New York, p 275-299

Kuwae T, Hosokawa Y, Eguchi N (1998) Dissolved inorganic nitrogen cycling in Banzu intertidal sand-flat, Japan. Mangr Salt Marshes 2:167-175

Malan DE, McLachlan A (1991) In situ benthic oxygen fluxes in a nearshore coastal marine system: a new approach to quantify the effect of wave action. Mar Ecol Prog Ser 73: $69-81$

Mukai H, Koike I (1984) Behavior and respiration of the burrowing shrimps Upogebia major (de Haan) and Callianassa japonica (de Haan). J Crustac Biol 4:191-200

Panofsky HA, Dutton JA (1984) Atmospheric turbulence: models and methods for engineering applications. John Wiley \& Sons, New York

Phillips OM (1977) The dynamics of the upper ocean. Cambridge University Press, London, p 37-43

Precht E, Huettel M (2003) Advective pore-water exchange

Editorial responsibility: Otto Kinne (Editor-in-Chief),

Oldendorf/Luhe, Germany driven by surface gravity waves and its ecological implications. Limnol Oceanogr 48:1674-1684

Precht E, Huettel M (2004) Rapid wave-driven advective pore water exchange in a permeable coastal sediment. J Sea Res 51:93-107

Precht E, Franke U, Polerecky L, Huettel M (2004) Oxygen dynamics in permeable sediments with wave-driven pore water exchange. Limnol Oceanogr 49:693-705

Reimers CE, Jahnke RA, Thomsen L (2001) In situ sampling in the benthic boundary layer. In: Boudreau BP, Jørgensen BB (eds) The benthic boundary layer. Oxford University Press, New York, p 245-268

Riedl RJ, Huang N, Machan R (1972) The subtidal pump: a mechanism of interstitial water exchange by wave action. Mar Biol 13:210-221

Rusch A, Huettel M (2000) Advective particle transport into permeable sediments - evidence from experiments in an intertidal sandflat. Limnol Oceanogr 45:525-533

Shimoda K, Tamaki A (2004) Burrow morphology of the ghost shrimp Nihonotrypaea petalura (Decapoda: Thalassinidea: Callianassidae) from western Kyushu, Japan. Mar Biol 144:723-734

Shirasawa K, Ingram RG, Hudier EJJ (1997) Oceanic heat fluxes under thin sea ice in Saroma-ko Lagoon, Hokkaido, Japan. J Mar Syst 11:9-19

Shum KT (1992) Wave-induced advective transport below a rippled water-sediment interface. J Geophys Res 97: 789-808

Shum KT (1993) The effects of wave-induced pore water circulation on the transport of reactive solutes below a rippled sediment bed. J Geophys Res 98:10289-10301

Stanzel C, Finelli C (2004) The effects of temperature and salinity on ventilation behavior of two species of ghost shrimp (Thalassinidea) from the northern Gulf of Mexico: a laboratory study. J Exp Mar Biol Ecol 312:19-41

Thomann RV, Mueller JA (1987) Principles of surface water quality modeling and control. Harper \& Row, New York

Uchiyama Y (2006) Hydrodynamics and associated morphological variations on an estuarine intertidal sand flat. J Coast Res (in press)

von Storch H, Zwiers FW (1999) Statistical analysis in climate research. Cambridge University Press, New York, p 279-281

Webb JE, Theodor JL (1968) Irrigation of submerged sands through wave action. Nature 220:682-683

Webster IT (1992) Wave enhancement of solute exchange within empty burrows. Limnol Oceanogr 37:630-643

Wenzhöfer F, Glud RN (2004) Small-scale spatial and temporal variability in coastal benthic $\mathrm{O}_{2}$ dynamics: effects of fauna activity. Limnol Oceanogr 49:1471-1481

Ziebis W, Huettel M, Forster S (1996a) Impact of biogenic sediment topography on oxygen fluxes in permeable seabeds. Mar Ecol Prog Ser 140:227-237

Ziebis W, Forster S, Huettel M, Jørgensen BB (1996b) Complex burrows of the mud shrimp Callianassa truncata and their geochemical impact on the sea bed. Nature 382: 619-622

Submitted: March 2, 2005; Accepted: August 18, 2005 Proofs received from author(s): December 19, 2005 